\title{
Brooke Modified Medical Research Council Manual Muscle Test Score, Lateral Rotation
}

National Cancer Institute

\section{Source}

National Cancer Institute. Brooke Modified Medical Research Council Manual Muscle

Test Score, Lateral Rotation. NCI Thesaurus. Code C139224.

The numerical value that represents the result of a clinical assessment of muscle strength and function during lateral rotation that is based on the Brooke Modified Medical Research Council Manual Muscle T est. (Brooke MH, Griggs RC, Mendell JR, Fenichel GM, et al. Clinical trial in Duchenne dystrophy. I. The design of the protocol. Muscle Nerve. 1981 May-Jun;4(3):186-97. doi:10.1002/mus.880040304). 